University of Nebraska - Lincoln

DigitalCommons@University of Nebraska - Lincoln

Uniformed Services University of the Health

Sciences

U.S. Department of Defense

2011

\title{
How to develop an effective obstetric checklist
}

\author{
M. Bardett Fausett \\ Wilford Hall Medical Center \\ Anthony Propst \\ Uniformed Services University of the Health Sciences \\ Karin Van Doren \\ Aviano Air Base \\ Benjamin T. Clark \\ McGuire Air Force Base
}

Follow this and additional works at: https://digitalcommons.unl.edu/usuhs

Part of the Medicine and Health Sciences Commons

Fausett, M. Bardett; Propst, Anthony; Van Doren, Karin; and Clark, Benjamin T., "How to develop an effective obstetric checklist" (2011). Uniformed Services University of the Health Sciences. 32. https://digitalcommons.unl.edu/usuhs/32

This Article is brought to you for free and open access by the U.S. Department of Defense at DigitalCommons@University of Nebraska - Lincoln. It has been accepted for inclusion in Uniformed Services University of the Health Sciences by an authorized administrator of DigitalCommons@University of Nebraska Lincoln. 


\section{How to develop an effective obstetric checklist}

Col M. Bardett Fausett, MD, USAF, MC; Col Anthony Propst, MD, USAF, MC;

Major Karin Van Doren, MSN, USAF, NC; Captain Benjamin T. Clark, USAF, JAGC

I $\mathrm{n}$ recent years, the use of protocols and checklists to guide care in select, critical situations has become a major focus of efforts to improve patient safety in both medical and nonmedical professional endeavors. ${ }^{1-6}$ We present in this study a review of general principles of checklist development, and an example of the process as implemented in a moderate sized health care system-the United States Air Force Medical Corps.

As early as 1999 , the use of checklists was advocated by the Institute of Medicine as an integral part of a larger effort to prevent medical error in the US health care system. ${ }^{7,8}$ The Institute of Medicine has stated that the standardization of key processes with the use of checklists and protocols is a key to the prevention of errors in health care systems and listed the definition of standards of practice as a primary role professional organizations should take in creating a culture of safety. ${ }^{7}$ Many specialties have adopted these recommendations-Figure $1 \mathrm{de}-$ tails the exponential growth of publications indexed by PubMed under "safety checklist" in the past 3 decades.

From the Wilford Hall Medical Center (Col Fausett, MD), Lackland AFB, TX; Uniformed Services University of the Health Sciences (Col Propst, MD), Bethesda, MD; Aviano Air Base (Major Van Doren), Aviano, Italy; McGuire Air Force Base (Captain Clark), Lakehurst, NJ.

Received Feb. 14, 2011; revised May 19 , 2011; accepted June 2, 2011.

Reprints not available from the authors.

The opinions expressed on this document are solely those of the author(s) and do not represent an endorsement by or the views of the United States Air Force, the Department of Defense, or the United States Government.

The authors report no conflicts of interest.

0002-9378/\$36.00

Published by Mosby, Inc.

doi: 10.1016/j.ajog.2011.06.003

Checklists to guide critical procedures are becoming an increasingly important part of medical practice. These tools have proved effective in improving outcome in a variety of medical settings, including obstetrics. In this review, we outline essential principles of successful checklist creation and implementation and review our experience with checklist development in a worldwide, multiinstitutional health care delivery system.

Key words: checklists, obstetric emergency, patient safety, United States Air Force (USAF)

The use of checklists has been demonstrated to be effective in improving outcomes in a variety of clinical settings, including the prevention of central-line associated infection, reduction in ventilator associated pneumonia in adults and children, improved compliance with clinical recommendations for the management of acute myocardial infarction and stroke, the administration of general anesthesia, diabetes care, and improved decision making in the diagnosis of brain death. ${ }^{1,2,9-16}$ General acceptance of the need for checklist-guided care in obstetrics has been slower, and largely limited to the past few years. Most efforts have been modeled after the groundbreaking programs developed by the Hospital Corporation of America to standardize the monitoring and administration of oxytocin, misoprostol, and magnesium sulfate, and the documentation of the management of shoulder dystocia. ${ }^{3,4}$ These approaches have been shown to significantly decrease both adverse outcomes and obstetric litigation in the nation's largest obstetric health care delivery system. ${ }^{4}$

Checklists adopted by high-reliability organizations typically take 1 of the following 4 forms ${ }^{2,17}$ :

1. Static parallel checklists typically are read and performed by a single individual. Published oxytocin administration checklists and those governing the use of anesthetic equipment are examples of this approach. ${ }^{3,16}$

2. Static sequential checklists with verification involve a "challenge and re- sponse" approach in which one individual reads a list and a second verifies completion of the requisite tasks. Many aircraft safety checklists, as well as those used for central line insertion and the administration of blood products are examples of this type of checklist. ${ }^{2,10,18}$

3. Static sequential checklists with verification and confirmation are typically used in larger team settings in contrast to a team of 2 as above. Such checklists are typically read by one team member with verification of task completion by multiple additional team members. Comprehensive operative room time outs often use this approach, which may also be applied to the management of shoulder dystocia (Figure 1). ${ }^{2,19}$

4. Dynamic checklists generally take the form of flow charts to guide clinical decision making. Flow charts lend to a visual display that is particularly useful when dichotomous decisions follow to different subsequent checklist items. Such checklists have been used to guide the intubation of patients with difficult airways, and more recently to assist in clinical decision making regarding the administration of magnesium sulfate for neuroprotection of premature infants and the management of hypertensive crisis in obstetrics (Figure 2). ${ }^{2,20}$ Checklists currently being developed for the management of category II fetal heart rate tracings will also likely take this form. 


\section{FIGURE 1}

\section{PubMed safety checklist articles}

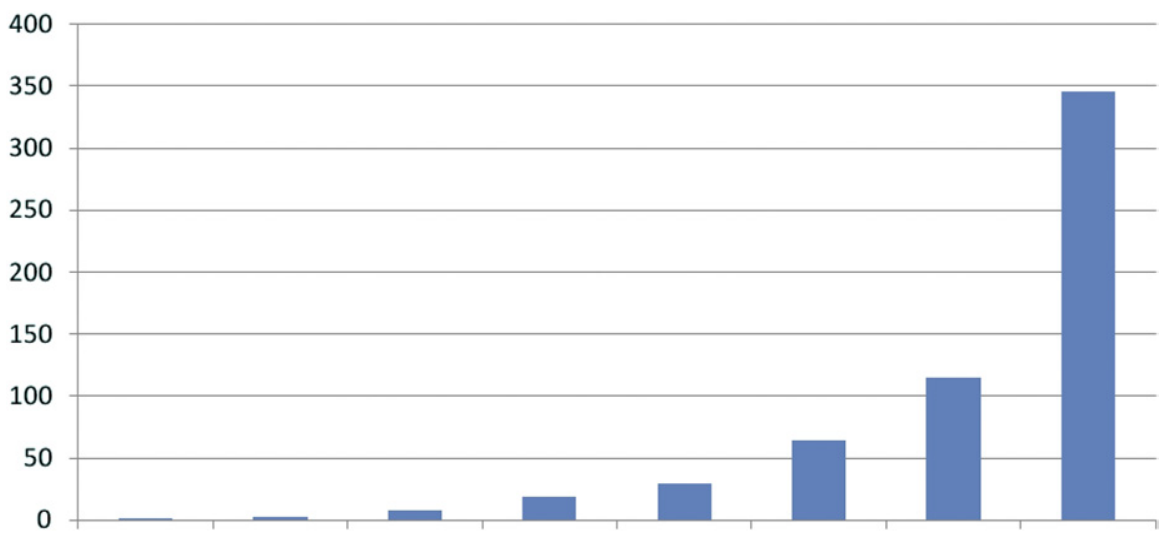

1970-1975 1976-1980 1981-1985 1986-1990 1991-1995 1996-2000 2001-2005 2006-2010

Fausett. How to develop an effective obstetric checklist. Am J Obstet Gynecol 2011.

Despite the evident importance of checklists to patient safety and quality improvement, no universally accepted processes exist for the effective development of medical checklists. Published recommendations regarding checklist development tend to suggest the importance of several key areas of checklist development. ${ }^{1,2,4,11,15}$ This approach may be outlined as follows:

1. Choose your clinical processes carefully. Not all medical conditions or procedures are amenable to management by checklist. In selecting processes or procedures for checklist development we suggest following closely the requirements set forth by the National Quality Forum for quality metric development. ${ }^{21}$ The following questions should be critically addressed for each potential checklist topic:

a. Is the topic of high importance? Is it currently associated with significant numbers of poor outcomes? Is there a gap between recommended and actual performance in your facility or community?

b. Is there a scientifically acceptable approach to effective diagnosis or treatment of the condition in question? Although the management of shoulder dystocia meets this criterion for checklist development, the management of amniotic fluid embolism does not. c. Does the development and implementation of a checklist have the enthusiastic support of senior and respected department medical and administrative leadership? Without such support, change will be slow, painful, and ineffective.

d. How intrusive will such a protocol be in the overall scheme of patient care? Will its implementation interfere with other, more critical processes? Will resource use be matched by expected clinical benefit? Does implementation of the checklist run the risk of devaluing other, more important checklists, and the development among clinicians of "checklist fatigue."

2. Processes are ideally developed by representatives of all groups (physicians and nurses) expected to implement the checklists. Often, an arbitrary initial "straw man" protocol will serve as an effective template for effective and efficient discussion and modification. Efforts of such working groups must be supported by strong clinical and administrative leadership.

3. Checklists should be short and unambiguous. It is better to break a complex process into several short, specific checklists rather than deal with a single cumbersome process.
4. Leave room for clinical judgment in exceptional cases. With a properly selected topic and a properly constructed checklist, such exceptions will be rare, and should be routinely subject to peer review.

5. Checklists should be reviewed frequently to assure ongoing compliance with new data and changing standards of care.

Incorporation of a checklist-based protocol approach to high-risk obstetric conditions seemed especially well suited to patient safety efforts of the US Air Force Medical Corps for several reasons.

First, military aviation was the birthplace of the checklist-based approach to reducing error in critical and complex situations, and is commonly cited as the inspiration for such practices adopted by other high-reliability organizations. ${ }^{1,2,4,18,22,23}$ This concept was born out of the experience of the US Army Air Corp with the B-17 bomber in World War II. After the crash in 1935 of an original prototype during an initial flight demonstration, the B-17 was deemed "too much plane for one man to fly." ${ }^{24}$ This realization led to the development of an entirely new approach to flying in which most critical portions of the operation were guided by uniform checklists; pilot autonomy was purposefully made subordinate to guidance by such protocols. In the next few years, the B-17 went from an abject failure to the workhorse of the American war effort and was a major factor in the eventual Allied victory. Ever since this experience, reliance on checklist-based protocols has been a mainstay of military and later commercial aviation. Indeed, even today, the aviation industry (military and civilian) remains the prototypical high-reliability organization against which all other such endeavors are compared. ${ }^{1,2,4,18,22-25}$

Based on this flight experience, checklists and protocols have become vital components of virtually all complex military procedures from mechanical maintenance to weapons readiness and even military law. Disciplinary charges of dereliction of duty across a wide variety of responsibilities are often based on failure to follow established protocols or check- 
lists. ${ }^{26}$ This approach has contributed significantly to the current status enjoyed by the US military as the preeminent fighting force in the world.

Finally, the realities of military medical practice include great degrees of mobility and change. A physician or nurse can be practicing in a military treatment facility in Alaska today, and in Italy tomorrow. Such conditions are not dissimilar to those experienced in many civilian settings in which physicians, nurses, or both may simultaneously practice in different hospitals with different cultures, patient populations, and medical teams. Thus changing teams and practice conditions would seem to make process standardization vital in both military medicine and in the civilian world. The recent development of checklists to guide critical process performance in US Air Force facilities provides a useful example of the above principles in practice.

In 2008, the Air Force Medical Operations Agency was established in San Antonio, TX, to assist in the centralization of personnel and policies across the US Air Force Medical Corps. In concert with this process, the Air Force Surgeon General's Perinatal Nursing, Obstetrics, and Gynecology, and Maternal-Fetal Medicine consultants began a united effort to bring to the specialty of obstetrics the same type of process standardization that has worked so well for other components of the military. This effort had several aspects:

1. The US Air Force Surgeon General's Maternal-Fetal Medicine Consultant was appointed to direct and oversee standardization efforts.

2. A patient safety task force was assembled, consisting of a representative obstetrician and/or maternal fetal medicine specialist and experienced obstetric nurses from each US Air Force medical facility with an obstetrics unit. The task force was assisted by a civilian patient safety consultant.

3. In consultation with these facility representatives, a list of 10 specific high priority situations in obstetric practice was developed. These were situations that were deemed by the team to pose particular challenges

\section{FIGURE 2}

\section{Blood pressure management of severe intrapartum or postpartum hypertension}

This document is intended as a guideline. It should be used as the default mode of practice for this procedure in the absence of a specific provider order to the contrary. Clinical situations exist in which alternative approaches to care are in the patient's best interest.

The following protocol should be initiated if the systolic blood pressure is $\geq 160$ $\mathrm{mmHg}$ OR the diastolic blood pressure is $\geq 110 \mathrm{mmHg}$.

_ Notify obstetrician

__Administer labetalol, $20 \mathrm{mg}$ IV over 2 minutes

_ Repeat blood pressure in 10 minutes

If either blood pressure threshold is still exceeded, administer labetalol, $40 \mathrm{mg}$ IV over 2 minutes.

_ Repeat blood pressure in 10 minutes

If either blood pressure threshold is still exceeded, administer labetalol, $60 \mathrm{mg}$ IV over 2 minutes and obtain emergency maternal-fetal medicine or internal medicine consultation.

\section{Repeat blood pressure in 10 minutes}

If either blood pressure criteria is still exceeded, administer hydralazine hydrochloride $10 \mathrm{mg}$ IV over 2 minutes.

Additional medication per specific order

Once above blood pressure thresholds are achieved, repeat blood pressure q 10 minutes for 1 hour, then $\mathrm{q} 15$ minutes $\mathrm{x} 1$ hour, then $\mathrm{q} 30$ minutes $\mathrm{x} 1$ hour, then blood pressures q hour $\mathrm{x} 4$ hours.

Additional blood pressure timing per specific order

IV, intravenous.

Fausett. How to develop an effective obstetric checklist. Am J Obstet Gynecol 2011.

with respect to patient safety and system error, based on existing medical literature and the experience of physicians and nurses on the task force (Table 1).

4. This list was prioritized, assisted by a comprehensive review of closed claims from all US Air Force facilities over the previous 5 years. We included the issues driving most of the claims suitable for potential intervention (Table 2).

5. Over the ensuing 24 months, highly specific protocols addressing the situations outlined in Table 1 were devel- oped and refined by the committee. We began with a centrally developed sample protocol that was then modified as necessary by the obstetric patient safety task force. This work was assisted by monthly audio and/or videoconferencing using Department of Defense electronic conferencing systems. In most cases, parallel nursing operating instructions (policy and procedures) were also developed. All of the work was performed by the nurse/physician task force thus avoiding discipline silos. These protocols were designed to be as brief and 


\section{TABLE 1 \\ Obstetric practice areas targeted for standardization

\begin{tabular}{|c|c|}
\hline No. & Practice area \\
\hline 1. & Oxytocin administration \\
\hline 2. & Magnesium sulfate infusion \\
\hline 3. & Misoprostol administration \\
\hline 4. & $\begin{array}{l}\text { Use of magnesium sulfate for } \\
\text { neuroprophylaxis }\end{array}$ \\
\hline 5. & Management of hypertensive crisis \\
\hline 6. & $\begin{array}{l}\text { Management of postpartum } \\
\text { hemorrhage }\end{array}$ \\
\hline 7. & Management of second stage labor \\
\hline 8. & $\begin{array}{l}\text { Shoulder dystocia-management } \\
\text { and documentation }\end{array}$ \\
\hline 9. & Operative vaginal delivery \\
\hline 10. & Management of eclampsia \\
\hline
\end{tabular}

specific as possible, and were developed in checklist form whenever feasible. A checklist is merely a more concise, clinically useful form of presenting a protocol. Examples are outlined in Figures 2 and 3. In some cases, we adopted or modified exist-

\section{TABLE 2 \\ Analysis of adverse outcomes}

Issue

Failure to perform cesarean delivery for select category II tracings, especially when complicated by other issues (eg, amnionitis, failure to progress)

Suboptimal documentation of indications procedures used in conjunction with operative vaginal delivery

Supoptimal documentation of maneuvers used to relieve shoulder dystocia.

Failure to respond to oxytocin-induced tachysystole even in the absence of worrisome fetal heart rate changes

Failure to adequately recognize and interpret FHR changes and possible need for cesarean delivery in cases of attempted vaginal birth after cesarean

Management of postpartum hemorrhage $F H R$, fetal heart rate.

Fausett. How to develop an effective obstetric checklist. Am J Obstet Gynecol 2011.

FIGURE 3

Management of shoulder dystocia

This document is intended as a guideline. It should be used as the default mode of practice for this procedure in the absence of a specific provider order to the contrary. Clinical situations exist in which alternative approaches to care are in the patient's best interest.

When shoulder dystocia is recognized:

1. Activate emergency system to get additional help

2. Avoid at all times the exertion of more force or traction on the fetal head than the gentle force that would be applied with a normal delivery.

3. Any fundal pressure is contraindicated prior to release of the shoulders.

4. The mother should be instructed to stop pushing unless specifically requested to do so.

5. Maneuvers for release of shoulder dystocia should be undertaken in the following order. Additional gentle traction may be undertaken during or following each maneuver to judge its effectiveness in releasing the shoulder:

a. McRoberts maneuver

b. Suprapubic pressure

c. Episiotomy or episiotomy extension if the thickness of the perineal body is judged to be contributing to the dystocia.

d. Woods' screw maneuver

e. Rubin's maneuver

f. Attempt Posterior arm release

g. Gaskin maneuver

h. Attempt clavicular fracture

i. Attempt Zavonelli's maneuver

j. Abdominal rescue

6. Maneuvers should be documented on the shouder dystocia delivery addendum form - electronic or written form.

Fausett. How to develop an effective obstetric checklist. Am J Obstet Gynecol 2011.

ing protocols. In other instances the protocols were unique.

6. Consensus was achieved by multidisciplinary discussion and agreement rather than military rank, title, or position. Once consensus had been achieved with respect to a specific protocol, it was implemented as a standard in all US Air Force facilities by directive of the Commanding General Officer of the Air Force Medical Operations Agency via a "Note to Airmen" (NOTAM). This document directed adoption of the checklists and associated operating instructions, assisted by the previously established team communications and simulator drills.
7. An ongoing internal audit process was then put into place to document compliance with established protocols. Deviation from established protocols with the use of alternative approaches is freely permitted in exceptional circumstances. The guidance at the top of the checklist suggests that optimal care sometimes requires deviation from the checklist. For example, a patient already on high-dose labetalol for chronic hypertension would clearly need a different approach to a hypertensive crisis than that outlined in Figure 2. However, such cases are subjected to peer review.

8. The checklists developed by the US Air Force have been published for use by 
TABLE 3

Mean scores in a postchecklist implementation questionnaire

\begin{tabular}{|c|c|c|c|c|c|}
\hline Variable & $\begin{array}{l}\text { Protocol addresses } \\
\text { an area of high } \\
\text { clinical importance }\end{array}$ & $\begin{array}{l}\text { There is a significant } \\
\text { gap between ideal } \\
\text { and actual team } \\
\text { performance in this } \\
\text { area }\end{array}$ & $\begin{array}{l}\text { Protocol is consistent } \\
\text { with the practice } \\
\text { of evidence-based } \\
\text { medicine }\end{array}$ & $\begin{array}{l}\text { Protocol will be } \\
\text { helpful to our } \\
\text { clinical team } \\
\text { in providing } \\
\text { good care }\end{array}$ & $\begin{array}{l}\text { Implementation } \\
\text { of the protocol } \\
\text { does not pose } \\
\text { an undue burden } \\
\text { on our clinical team }\end{array}$ \\
\hline 0xytocin & 4.9 & 2.5 & 5 & 5 & 5 \\
\hline Magnesium sulfate & 4.8 & 2.0 & 4.0 & 4.9 & 4.3 \\
\hline Misoprostol & 4.7 & 2.2 & 4.8 & 4.8 & 4.3 \\
\hline Shoulder dystocia & 5.0 & 3.0 & 4.8 & 4.8 & 4.7 \\
\hline Hypertensive crisis & 5.0 & 3.0 & 4.4 & 4.9 & 4.5 \\
\hline $\begin{array}{l}\text { Postpartum } \\
\text { hemorrhage }\end{array}$ & 4.9 & 2.8 & 4.8 & 5.0 & 4.8 \\
\hline Neuroprophylaxis & 4.8 & 2.6 & 4.9 & 4.9 & 4.7 \\
\hline Eclampsia & 5.0 & 2.7 & 5.0 & 5.0 & 4.8 \\
\hline $\begin{array}{l}\text { Second stage } \\
\text { management }\end{array}$ & 4.5 & 2.7 & 4.9 & 4.2 & 4.7 \\
\hline $\begin{array}{l}\text { Operative vaginal } \\
\text { delivery }\end{array}$ & 4.8 & 2.7 & 5.0 & 4.9 & 4.8 \\
\hline
\end{tabular}

our sister services, and are available, by request, for use in civilian facilities.

After development and implementation of these checklists according to the above process, we surveyed the physicians and nurses in the 12 facilities involved in this project regarding the effect of this process on patient safety. This survey involved 17 physician leaders ( 12 obstetrician/gynecologists and 5 maternal-fetal medicine specialists) and 15 nurse leaders. Our questions were designed to mirror the criteria adopted by the National Quality Forum in the evaluation of potential quality performance metrics (Table 3) ${ }^{27}$ However, in our survey, 1 specific question was purposefully asked twice, using different language (questions 2 and 4, Table 3). As demonstrated in Table 3, participants ranked these protocols highly in terms of clinical importance of the topic addressed, scientific validity of the protocol developed, and ability to be integrated into clinical practice without undue burden on the clinical team. When asked to rate the gap between the specific respondent's actual prechecklist performance and ideal performance, most clinicians thought the gap was small; however, when asked whether the same checklist would be helpful in a general sense in providing good care, respondents ranked the protocol highly. We found this difference fascinating, as it highlights one obstacle to the widespread acceptance of a checklist-based approach to critical medical processes: even excellent clinicians tend to be defensive when faced with the emotional challenge of standardizing their own current practice, whereas the same clinicians generally see the value of such an approach when the question is asked in the abstract, and applies to future care given by clinicians in general.

Our efforts in practice standardization were based on a central premise that applies to virtually all human endeavors requiring team management. Even if several approaches to a specific situation are individually equivalent in terms of patient outcome, choosing 1 of these approaches and implementing it the same way every time will yield results superior to those achieved by random use of various individually valid protocols. ${ }^{4,28,29} \mathrm{~A}$ successful checklist does not have to be based on a proven best practice (such as multiple randomized clinical trials) when the existence of such a proven best practice is not present. Rather, developers simply need to select one approach that is as good as any others, and then assure that it is used consistently and uniformly by all team members. Uniformity alone will improve outcomes, compared with the random use of multiple protocols that are, in isolation, equally effective.

Widespread acceptance across the US Air Force Medical Service has been challenging despite the fact that the larger US Air Force uses checklists frequently. The Medical Corp trains and functions similar to the civilian medical community. Thus, even in the military this approach contrasts with traditional models of medical care in which physician autonomy is a primary concern. Our education efforts have focused on the concept that although autonomy in some aspect is reduced with the use of a disciplined use of uniform protocols, the checklists facilitate collaborative management of these common obstetric challenges magnifying physician autonomy to deal with other complex issues. Poor team preparation and communication failures in emergency situations ultimately increase the likelihood of adverse outcomes and 
litigation resulting in diminished autonomy. Demands on physician time and attention, mandate the collaborative use of skilled nursing and other support staff making obstetrics a "team sport."

Obstetrics today remains a complex process that is, like military and commercial aircraft, "too much plane for one man to fly." Checklists are an integral part of a safer medical system advocated by the Institute of Medicine in which "reliance on memory and vigilance" are to be avoided. ${ }^{7,8}$ Our experience provides a concrete example of the successful application of the principles for checklist development discussed previously. Unlike all humans, the checklist never forgets.

We are confident that our approach, with appropriate modifications, may provide a valuable guide to the implementation of those types of systems change advocated by the Institute of Medicine as essential to improvement of patient safety. With appropriate and committed leadership, the development and institution of checklists has become well accepted across a geographically and demographically diverse population within the US Air Force. Our experience suggests that such efforts will require the expenditure of considerable energy and resources, in addition to innovative leadership. However, a comparison of the safety record of military and commercial aviation with that of American medicine suggests that with respect to patient safety, such efforts are well worth it. ${ }^{30}$

\section{REFERENCES}

1. Hales B, Terblanche M, Fowler R, et al. Development of medical checklists for improved quality of medical care. Int J Qual Health Care 2007;20:22-30.
2. Winters BD, Gurses AP, Lehman $H$, et al. Clinical review: checklists-translating evidence into practice. Crit Care 2009;13:210-5.

3. Clark SL, Belfort MA, Saade GA, et al. Implementation of a conservative, checklist based protocol for oxytocin administration: maternal and fetal outcomes. Am J Obstet Gynecol 2007; 197:480.e1-5.

4. Clark SL, Belfort MA, Meyers JA, et al. Improved outcomes, fewer cesarean deliveries and reduced litigation: results of a new paradigm in patient safety. Am J Obstet Gynecol 2008;199;105.e1-7.

5. Hayes EJ, Weinstein L. Improving patient safety and uniformity of care by a standardized regimen for the use of oxytocin. Am J Obstet Gynecol 2008;198:622.e1-7.

6. Freeman RK, Nageotte M. A protocol for the use of oxytocin. Am J Obstet Gynecol 2007; 197:445-6.

7. The Institute of Medicine. To err is human: building a safer health system. National Academy of Sciences, National Academies Press, Washington, DC; 1999.

8. The Institute of Medicine. Crossing the quality chasm. National Academy of Sciences, National Academies Press, Washington, DC; 2001. 9. Schectman JM, Schorling JB, Nadkarni MM, et al. The effect of physician feedback and an action checklist on diabetes care measures. Am J Med Qual 2004;19:207-15.

10. Provonost $P$, Needham $D$, Berenholtz $S$, et al. An intervention to decrease catheter-related bloodstream infections in the ICU. N Eng J Med 2006;355:2725-32.

11. Hales BM, Provonost PJ. The checklist - a tool for error management and performance improvement. J Crit Care 2006;21:231-5.

12. Young GB, Frewen T, Barr HW, et al. Checklist for the diagnosis of brain death. Can J Neurol Sci 1991;18:104.

13. Walsh TS, Dodds S. McArdle F. Evaluation of simple criteria to predict successful weaning for mechanical ventilation in intensive care patients. Br J Anaesth 2004;92:793-9.

14. Hart EM, Owen H. Error and omissions in anesthesia: a pilot study using a pilot's checklist Anesth Analg 2005;401:246-50.

15. Thomassen O, Brattebo G, Heltne JK, et al. Checklists in the operating room: help or hurdle? A qualitative study on health workers' ex- periences BMC. Health Serv Res 2010;10: 342-6.

16. Kendall A, Barthram C. Revised checklist for anesthetic machines. Anaesthesia 1998;53: 887-90.

17. Peleg M, Boxwala AA, Ogunyemi O, et al. GLIF 3: the evolution of a guideline representation format. Proc AMIA Symp 2000:645-9.

18. Degani A, Weiner EL. Cockpit checklists: concepts, design and use. Human Factors 1993;35:28-43.

19. Makary MA, Holzmueller CG, Thompson DA, et al. Operating room briefings: working on the same page. Jt Comm J Qual Patient Saf 2006;32:351-5.

20. Reeves S, Gibbs, R, Clark SL. Magnesium for fetal neuroprotection. Am J Obstet Gynecol 2011;204:202.e1-4.

21. The National Quality Forum. NQF \#0469. Elective delivery prior to 39 completed weeks gestation. Endorsed on: Oct. 28, 2008. Available at: http://qualityforum.org/Measures_List. aspx. Accessed Nov. 9, 2009.

22. Bevea SC. Highly reliability theory and reliable organizations. AORN J 2005;81:1319-22. 23. Belfort MA. Shoulder dystocia and flying airplanes. Obstet Gynecol 2004;104:658-60.

24. Gawande A. The checklist. The New Yorker. December 10, 2007.

25. Rochlin Gl, LaPorte TR, Roberts KH. The Self designing high reliability organization: aircraft carrier flight operations at sea. Available at: http://www.caso-db.uvek.admin.ch/Documents/ MTh_SM_22.pdf. Accessed Nov. 8, 2010.

26. Castellon D. A string of mistakes (live vs. blank ammo). Available at: http://www. freerepublic.com/focus/f-news/795506/posts. Accessed Nov. 8, 2010.

27. National Quality Forum Endorsed Standards. Available at: www.quality forum.org. Accessed Jan. 27, 2011.

28. Wennberg JE. Unwarranted variations in healthcare delivery: implications for academic medical centers. BMJ 2002;325:961-5.

29. Pronovost PJ, Holzmueller CF, Ennen CS, Fox HE. Overview of progress in patients safety. Am J Obstet Gynecol 2011;1:5-10.

30. Federal Aviation Administration. Safety record of airlines/aircraft. Available at: http://www. faa.gov/passengers/fly_safe/safety_record/. Accessed Nov. 8, 2010. 